\title{
Difference between ferritin genes overexpressing in transgenic tobacco
}

\author{
X. Tang ${ }^{1,2}$, D. Zou ${ }^{2}$, L. Zhang', C. Yang ${ }^{1}$ and T. Jiang ${ }^{1}$ \\ ${ }^{1}$ State Key Laboratory of Forest Genetics and Tree Breeding, \\ Northeast Forestry University, Harbin, China \\ ${ }^{2}$ College of Agriculture, Northeast Agricultural University, Harbin, China \\ Corresponding authors: C. Yang / T. Jiang \\ E-mail: nefuycp@sina.com / xuts98@163.com
}

Genet. Mol. Res. 13 (2): 3176-3185 (2014)

Received December 10, 2013

Accepted March 28, 2014

Published April 25, 2014

DOI http://dx.doi.org/10.4238/2014.April.25.2

\begin{abstract}
With the development of molecular biology techniques, intron was known as playing an imperative role in gene's expression and regulation. Transgenic tobacco IN lines overexpressing InFerl gene and NT lines overexpressing NtFer1 cDNA gene were obtained, and the exogenous gene expression were confirmed by molecular test. Then for iron content of transgenic tobacco lines and non-transformants as a physiological indicator in status of different iron concentration were measured, and results indicated that the iron content of transgenic tobacco was more than that of non-transformants. In high $\mathrm{Fe}$ (II) condition, the NT lines showed higher level in plant height, fresh weight and iron content then that of IN lines, while NT lines showed lower in Malondialdehyde content then IN lines. In soil condition, IN lines showed higher level in plant height, fresh weight, chlorophyll, photosynthesis rate, iron content then that of NT lines. It indicates that intron could play a vital role for improved protective enzyme activity level while reducing reactive oxygen damage and also could help to inhibit the absorption of aborting iron.
\end{abstract}

Key words: Ferritin; Intron; Iron content; Tobacco 


\section{INTRODUCTION}

Iron $(\mathrm{Fe})$ is a chemical element that is universally abundant and plays a vital role in biological processes (Dlouhy and Outten, 2013), such as forming complexes with molecular oxygen in hemoglobin and myoglobin. It is also present at the active sites of many important redox enzymes involved in cellular respiration (i.e., oxidation reduction processes in plants and animals). Ferritin genes have been documented in plants, animals, and microbes (Theil, 1987; Proudhon et al., 1996; Andrews, 1998; Harrison et al., 1998; Carrondo, 2003; Pham et al., 2004). In addition to storing iron, ferritin may also be involved in ferroxidase activity, immune responses, mitochondrial stress responses, yolk, and industrial applications.

Genetic engineering techniques have been applied in numerous fields, including research, agriculture, industrial biotechnology, and medicine. They can be used to increase growth rates and resistance to different diseases caused by pathogens and parasites. The modified crops would also reduce the usage of chemicals such as fertilizers and pesticides; thus decreasing the severity and frequency of the damages produced by these chemical pollutants (Carrington, 2012). For the current research, it provides a useful method for studying gene expression and functions; thus, a particular gene was introduced into a plant to test its role.

An intron opposite of the exon, often referred to as "junk DNA", is a nucleotide sequence within a gene that is removed by RNA splicing, while the final mature RNA product of the gene is being generated (Bruce, 2008). The underlying mechanisms of introns are still ambiguous; however, some of these mechanisms have been verified by encoding a specific protein or generate noncoding RNA (Rearick et al., 2011), which may be involved in the recombination of separated exons and participates in the evolution of new proteins (Darnell, 1978; Gilbert, 1978).

Few studies have focused on the intron roles in gene expression. The objectives of the current study were to: a) introduce the ferritin gene (exon plus intron and exon only) into tobacco and b) investigate the difference between these 2 transgenic tobacco lines to identify whether the intron is silent in gene expression.

\section{MATERIAL AND METHODS}

\section{Plasmid construction}

Tobacco leaves were harvested $24 \mathrm{~h}$ after the transfer of plantlets from a nutrient solution containing no iron to a nutrient solution containing Fe-EDTA. A pair of primers (5'-GCGACTAGTCCATGCTTCTCAAGGCGG-3' and 5'-GCGAGCTCCTTCAAGCAGCA GCTCC-3') was designed to generate a 756-bp fragment containing SpeI and SacI restriction sites of the NtFerl gene via polymerase chain reaction (PCR). Another pair of primers (5'-GCGACTAGTCCTCACCACACACTGAATTTCGCC-3' and 5'-GCGCTCGAGCTTCA AGCAGCAGCTCCCTCATTC-3') was designed via PCR to generate a 1996-bp fragment containing the SpeI and XhoI restriction sites of the InFerl gene. The PCR products were digested by the restriction sites and then inserted into the plasmid PBI121. GUS was excised in the newly generated plasmid.

\section{Plant transformation and regeneration}

The newly generated plasmid was transferred into the Agrobacterium tumefaciens 
strain EHA105 by electro-transformation; then, the transformants were obtained by the leaf disc transformation method. Transformants and regeneration of tobacco plants (Nicotiana tabacum L. 'Petit Havana SR-1') were cultured on Murashige and Shoog (MS) medium (100 $\mathrm{mg} / \mathrm{L}$ kanamycin) and termed the $\mathrm{T}_{0}$ generation.

\section{PCR, Southern blot, and Northern blot analysis}

PCR test primers were designed according to the NtFerl and InFer 1 genes (5'-CCACT ATCCTTCGCAAGACCCTTCC-3' and 5'-CATCGCAAGACCGGCAACAGGATTC-3').

Total genomic DNA was extracted from fresh leaves by the cetyl trimethyl ammonium bromide method (Murray and Thompson, 1980) and used to conduct the PCR analysis. The PCR was performed in a total volume of $20 \mu \mathrm{L}$ containing $1.0 \mu \mathrm{L}$ DNA, 10 pmol each primer, $1 \mathrm{X}$ PCR buffer, $10 \mu \mathrm{mol}$ dNTPs, $1 \mathrm{X} \mathrm{MgCl}_{2}$, and $0.5 \mathrm{U}$ Taq polymerase (TaKaRa, Dalian, China). The PCR reaction was carried out by denaturing the template at $94^{\circ} \mathrm{C}$ for 2 min followed by 30 cycles of amplification $\left(30 \mathrm{~s}\right.$ at $94^{\circ} \mathrm{C}, 30 \mathrm{~s}$ at $58.5^{\circ} \mathrm{C}$, and $2 \mathrm{~min}$ at $72^{\circ} \mathrm{C}$ ), and an extension at $72^{\circ} \mathrm{C}$ for $10 \mathrm{~min}$.

Southern blot analysis (Engler-Blum et al., 1993) was further used to confirm the transgenic status of positive plants by PCR analysis. The complementary DNA was marked by PCR primers and the PCR DIG Probe Synthesis Kit (Roche, Switzerland) was used as the probe. RNA extraction was conducted using TRIzol (Reagent, Carlsbad, CA, USA) for Northern blot analysis; $30 \mu \mathrm{g}$ RNA was denatured at $100^{\circ} \mathrm{C}$ for $5 \mathrm{~min}$, then separated from $1 \%$ agarose/formaldehyde gel through electrophoresis. The methodology and probe used were the same as those in the Southern blot analysis.

\section{Culture of the $T_{1}$ generation}

The seeds of $\mathrm{T}_{0}$ (i.e., IN: InFer 1 gene transgenic plants and NT: NtFerl gene transgenic plants) were collected and grown on MS medium (100 mg/L kanamycin) for further research. The resistant seedlings and nonresistant seedlings were counted separately to calculate the ratio.

After 15 days, 3 replicates of each transgenic tobacco line were transplanted to MS medium [containing $100 \mathrm{mg} / \mathrm{L}$ kanamycin, $300 \mu \mathrm{M} \mathrm{Fe}$ (II), and soil]. After 30 days, the plants grown in the MS medium were tested for physiological characteristics, and 60-day-old soilgrown plants were tested for physiological characteristics and photosynthetic parameters.

\section{Iron extraction and measurements}

For iron extraction and analysis, the samples were obtained from the top leaves. The leaves were dried at $60^{\circ} \mathrm{C}$, ground, and mineralized $(0.1 \mathrm{~g}$ dry matter). The Fe concentration was measured by assessing the absorbance of Fe at $248.3 \mathrm{~nm}$ using an Atomic Absorption Spectrophotometer (Z-2000, Hitachi, Japan).

\section{Physiological test of transgenic tobacco under Fe (II) stress}

The height and fresh weight of all samples were tested, and the leaf chlorophyll content of the top leaf was measured by the chlorophyll meter SPAD-520 (Minolta, Japan). Subsequently, the materials were prepared for other index measurements. In higher plants, super- 
oxide dismutase enzymes (SODs) act as antioxidants and protect cellular components from oxidation by reactive oxygen species (ROS) (Alscher et al., 2002); SODs were measured by the nitro blue tetrazolium chloride method (Giannopolitis and Ries, 1977).

MDA is one of the final decomposition products of lipid peroxidation and has been used as an index for the status of lipid peroxidation. The levels of MDA contents were determined by the thiobarbituric acid (TBA) reaction as described by Stewart and Bewley (1980), with some modifications. One gram of leaves (FW) was homogenized in $4 \mathrm{~mL} 0.5 \%(\mathrm{w} / \mathrm{v})$ TCA. The homogenate was centrifuged at $10,000 \mathrm{~g}$ for $10 \mathrm{~min}$ and $4 \mathrm{~mL} 20 \%$ TCA containing TBA $0.5 \%(\mathrm{w} / \mathrm{v})$ was added to $1 \mathrm{~mL}$ supernatant. The mixture was heated at $95^{\circ} \mathrm{C}$ for 20 min, quickly cooled on ice, and then centrifuged at $10,000 \mathrm{~g}$ for $10 \mathrm{~min}$; the absorbance of the supernatant was taken at 532 and $600 \mathrm{~nm}$. After subtracting the nonspecific absorbance at $600 \mathrm{~nm}$, the MDA concentration was determined by its extinction coefficient of $155 \mathrm{mM} / \mathrm{cm}$.

\section{Physiological test of transgenic tobacco planted in soil}

The leaf chlorophyll content was measured by the chlorophyll meter SPAD-520 (Minolta, Japan), Net photosynthetic rate, transpiration rate, and stomatal conductance were measured by LI6400 (LI-COR, USA), and the iron content of the leaves was measured by atomic absorption spectrophotometer.

\section{RESULTS}

\section{Analysis of putative transgenic plants}

After transformation by the Agrobacterium tumefaciens infection method, the InFer 1 gene transgenic plant (IN) and NtFerl gene transgenic plant (NT) transformants were selected with kanamycin $(100 \mathrm{mg} / \mathrm{L})$. The $\mathrm{T}_{0}$ generation of the IN and NT lines were selected for PCR confirmation and then verified. The seeds of the $\mathrm{T}_{0}$ transgenic tobacco were collected and germinated on MS medium ( $100 \mathrm{mg} / \mathrm{L}$ kanamycin). The $5 \mathrm{InFer} 1$ transgenic tobacco lines (IN 1-5) and $5 \mathrm{NtFer1}$ transgenic tobacco lines (NT 1-5) were selected for further research. As shown in Table 1, the separation ratio of IN-6 and NT-6 was 15:1, which may be caused by the cloning of the 2 fragments into 2 nonhomologous chromosomes; this was not our research objective. IN 1-5 and NT 1-5 were separated into a ratio of 3:1, which showed that a single clone was integrated within the genome of interest.

\begin{tabular}{|c|c|c|c|c|c|}
\hline Lines & Total plants (No.) & Resistant plants (A) & Sensitive plants (a) & Expected rate & $\chi^{2}$ value \\
\hline IT-1 & 67 & 51 & 16 & $3: 1$ & 0.0049 \\
\hline IT-2 & 42 & 32 & 10 & $3: 1$ & \\
\hline IT-3 & 59 & 44 & 15 & $3: 1$ & 0.0059 \\
\hline IT- 4 & 54 & 38 & 16 & $3: 1$ & 0.2960 \\
\hline IT-5 & 47 & 36 & 11 & $3: 1$ & 0.0071 \\
\hline IT-6 & 77 & 68 & 9 & $15: 1$ & 3.0138 \\
\hline NT-1 & 99 & 77 & 22 & $3: 1$ & 0.3367 \\
\hline NT-2 & 60 & 48 & 12 & $3: 1$ & 0.5203 \\
\hline NT-3 & 87 & 68 & 19 & $3: 1$ & 0.3103 \\
\hline NT-4 & 85 & 67 & 18 & $3: 1$ & 0.4745 \\
\hline NT-5 & 45 & 34 & 11 & $3: 1$ & 0.0056 \\
\hline NT-6 & 72 & 65 & 7 & $15: 1$ & 0.9481 \\
\hline
\end{tabular}




\section{PCR test, Southern blot, and Northern blot}

Total DNA was extracted from the mature leaves of kanamycin-resistant plants and used in the PCR to analyze the presence of the introduced ferritin gene (IN and NT). A set of PCR primers was designed to amplify a 1996-bp sequence that contained InFer1, and a 756-bp sequence that contained NtFer1. Figure 1a shows the specific bands of the InFer 1 and NtFer1 genes in 5 tobacco lines (one individual per line, identical results were obtained from the other individuals of each line, data not shown). Southern blot analysis was carried out with the genomic DNA of transformants and the nontransgenic plants (SR) (Figure 1b). Northern blot was carried out to verify gene expression in the transformants (Figure 1c, d). The results showed that the exogenous gene was expressed in the transformants.

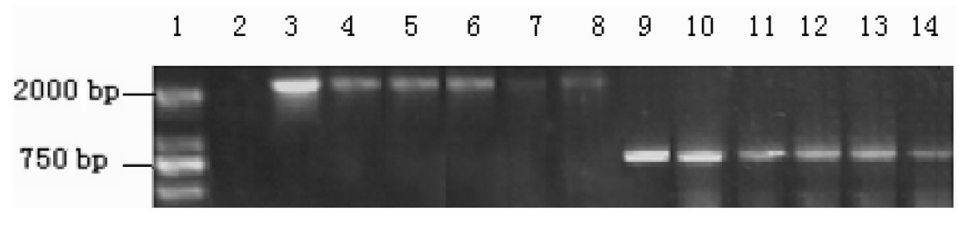

(a)

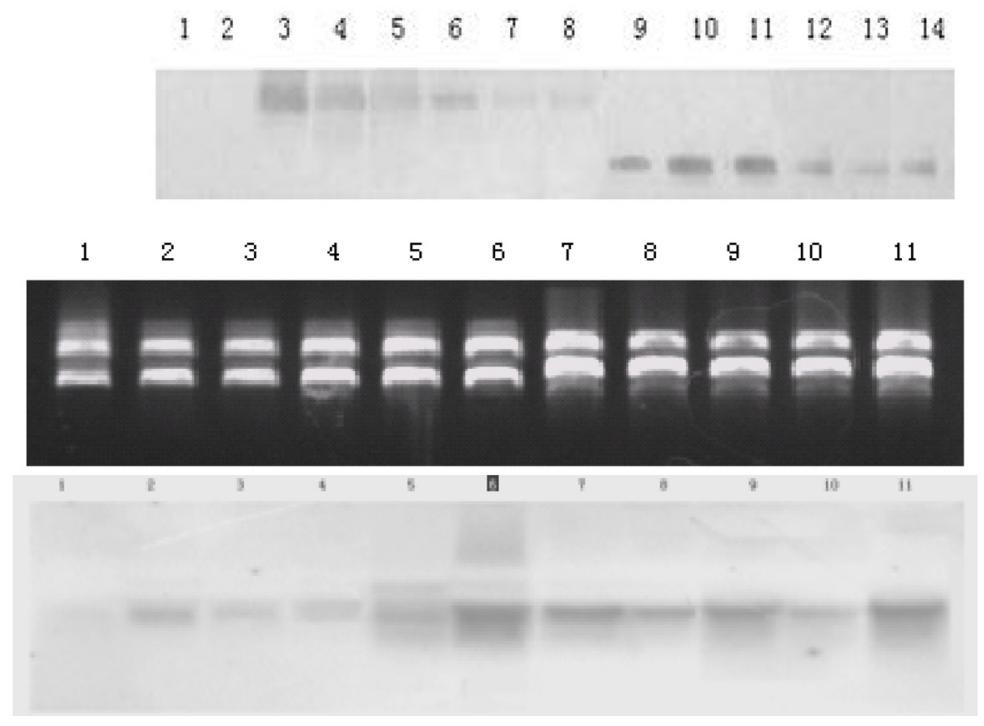

(b)

(c)

Figure 1. Test analysis of InFer1 transgenic tobacco lines (IN) and NtFer1 transgenic tobacco lines (NT) transgenic tobacco plants. a. Polymerase chain reaction (PCR) analysis of transgenic tobacco plants. b. PCR-Southern blot analysis of IN and NT generation plants. c. Electrophoresis of total RNA treated with RNase-free DNase. d. Northern blot analysis of ferritin expression. a. b. Lane 1 = DNA molecular weight marker DL2000; lane 2 = nontransformant; lane 3 = IN plasmid positive control; lanes 4-8=IN1-IN5; lane 9, NT plasmid positive control; and lanes 10-14, NT1-NT5. c. d. Lane $1=$ non-transformant; lanes 2-6=IN1-IN5; and lanes 7-11= NT1-NT5.

\section{Test of transgenic tobacco under Fe (II) stress}

Transformants and nontransgenic plants were grown in MS medium containing 300 $\mu \mathrm{mol} / \mathrm{L}$ Fe (II). Thirty days later, growth and physiology were evaluated; transgenic lines and 
SR test results are shown in Figure 1. The average height of the IN transgenic tobacco lines was 25.7 and $31.1 \%$ less than that of the SRs and NT transgenic lines, respectively. The average fresh weight of the IN transgenic tobacco lines was 18.9 and $30.3 \%$ less than that of the SRs and NT transgenic lines, respectively. The height and weight were significantly different between SR, IN, and NT (Figure 2a, b). Differences in the relative chlorophyll content were not significant between all lines (Figure 2c).
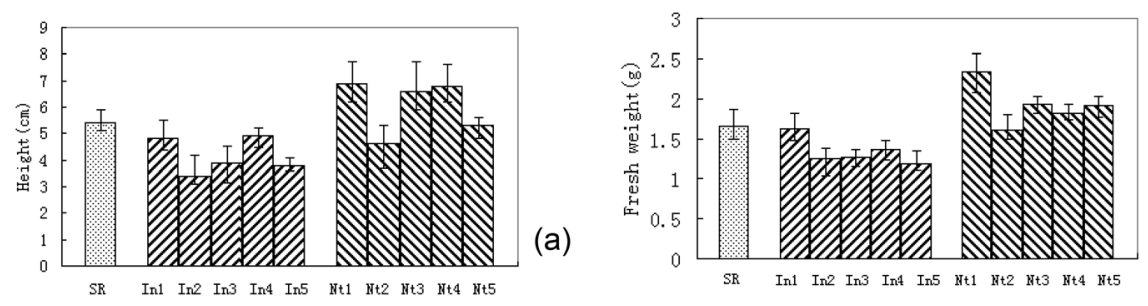

(b)
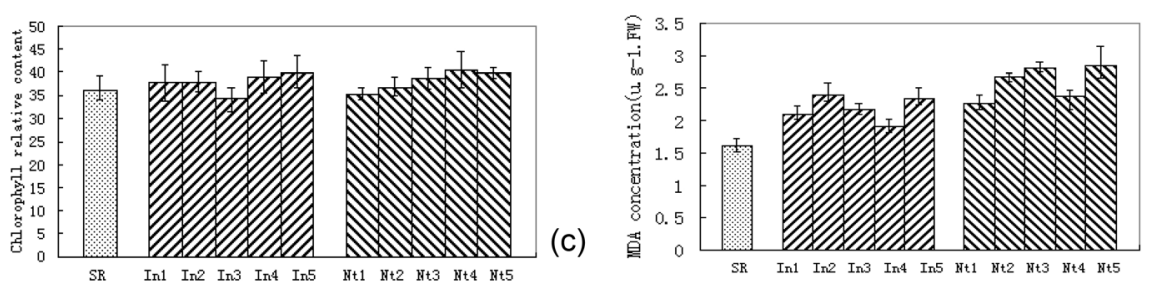

(d)
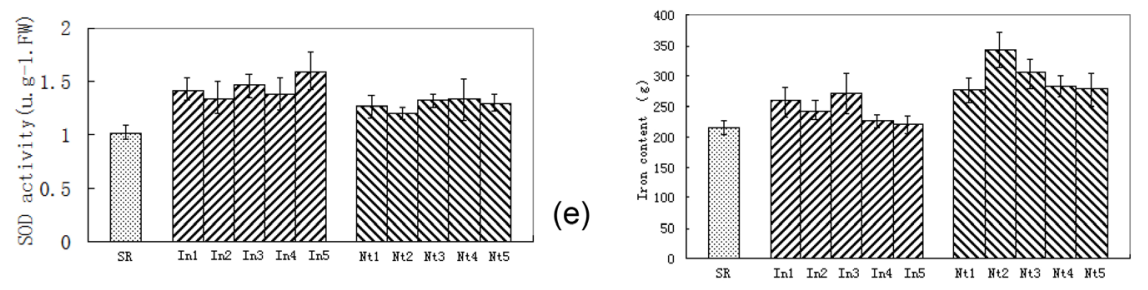

(f)

Figure 2. Comparison between transgenic tobacco plants and non-transformants grown in supplemented MS media. a. Comparison of the heights between IN, NT, and SR. b. Comparison of the fresh weights between IN, NT, and SR. c. Comparison of the chlorophyll relative contents of IN, NT, and SR. d. Comparison of malondialdehyde (MDA) contents in the leaves of IN, NT, and SR. e. Comparison of superoxide dismutase (SOD) contents in the leaves of IN, NT, and SR. f. Comparison of total iron relative contents in the leaves of IN, NT, and SR.

The MDA content reflected varied grades of cellular damage. The average MDA content of IN transgenic tobacco lines was 36.5\% higher than that of the SRs and $15.9 \%$ less than that of the NT transgenic lines (Figure 2d). SODs catalyze the production of $\mathrm{O}_{2}$ and $\mathrm{H}_{2} \mathrm{O}_{2}$ from superoxide $\left(\mathrm{O}^{2-}\right)$, which resulted in less harmful reactants. The average SOD content of IN transgenic tobacco lines was $41.0 \%$ more than that of the SRs and $12.0 \%$ higher than that of the NT transgenic lines (Figure 2e).

The average iron content of the controls (SRs) was $216.0 \mu \mathrm{g} / \mathrm{g}$ dry weight. The average iron content of the transformants (NT2) was 1.6- and 1.4-fold higher than that of the controls and IN lines, respectively. The average iron content of the IN transgenic tobacco lines was $12.9 \%$ higher than that of the SRs and $17.8 \%$ lower than that of the NT transgenic lines (Figure 2f). 


\section{Test of transgenic tobacco planted in soil}

After 60 days, when the SR, IN, and NT transgenic lines were transplanted to soil, they were tested for height, fresh weight, chlorophyll, net photosynthetic rate, transpiration rate, $\mathrm{H}_{2} \mathrm{O}$ conductance, and total relative iron content.

The average height and fresh weight of IN transgenic tobacco lines increased at the highest rate after 60 days. The height of IN transgenic tobacco lines were 12.8 and $4.8 \%$ greater than that of the SR and NT transgenic lines, respectively. The fresh weight of IN transgenic tobacco lines was 12.0 and $4.9 \%$ greater than that of the SR and NT transgenic lines, respectively (Figure 3a, b).

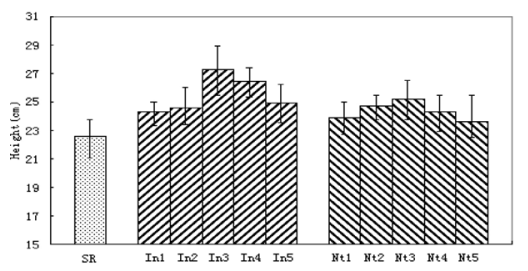

(a)

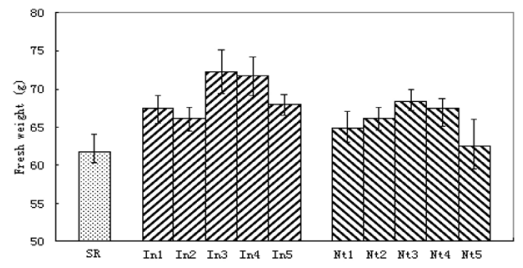

(b)
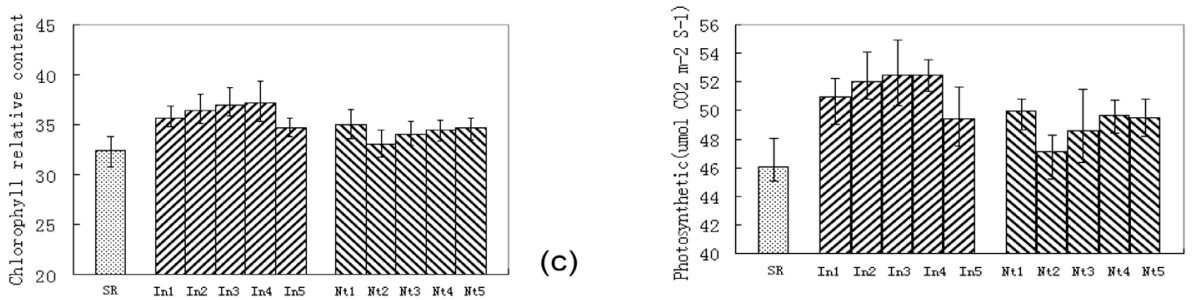

(d)
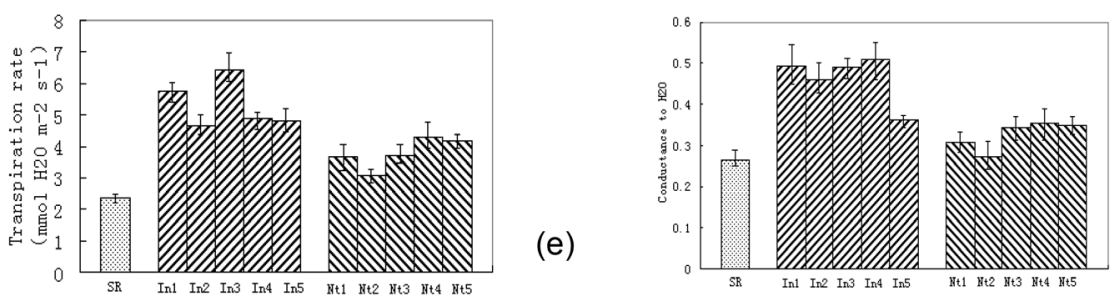

(f)

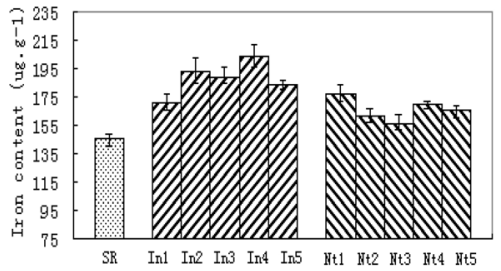

(g)

Figure 3. Comparison between transgenic tobacco plants and non-transformants grown in soil. a. Comparison of the heights between IN, NT, and SR. b. Comparison of the fresh weights between IN, NT, and SR. c. Comparison of the chlorophyll relative contents of IN, NT, and SR. d. Comparison of the net photosynthetic rates of IN, NT, and SR. e. Comparison of the transpiration rates of IN, NT, and SR. f. Comparison of the conductance to $\mathrm{H}_{2} \mathrm{O}$ of IN, NT, and SR. g. Comparison of total relative iron content in the leaves of IN, NT, and SR. 
Chlorophyll is vital for photosynthesis; it allows plants to absorb energy from light (Stein Carter, 1996). Iron is needed to produce chlorophyll; hence, its deficiency causes chlorosis. The average chlorophyll content of the IN transgenic tobacco lines was 12.4 and 5.8\% greater than that of the SR and NT transgenic lines, respectively (Figure 3c). The net photosynthetic rate of the IN transgenic tobacco lines was 11.8 and $5.1 \%$ greater than that of the SR and NT transgenic lines, respectively (Figure 3d). Photosynthesis, transpiration rate, and conductance are closely related. The average transpiration rate of the IN transgenic tobacco lines was 123.3 and $39.7 \%$ greater than that of the SR and NT transgenic lines, respectively. The $\mathrm{H}_{2} \mathrm{O}$ conductance to the IN transgenic tobacco lines was 74.5 and $42.1 \%$ greater than that of the SR and NT transgenic lines, respectively (Figure 3e, f).

The average iron content of the control samples (SRs) was $145.7 \mu \mathrm{g} / \mathrm{g}$ dry weight. The highest iron content of the transformant (IN4) contained 1.4-fold higher amounts of iron than the controls and $22.46 \%$ more than the average of the NT lines. The total relative iron content of the IN transgenic tobacco lines was $28.9 \%$ more than that of the SRs and $13.2 \%$ more than that of the NT transgenic lines (Figure $3 \mathrm{~g}$ ).

\section{DISCUSSION}

In the current experiment, materials for indicator measurements were obtained from the top part of the tobacco plant because iron mostly presents as a polymer that exhibits decreased mobility and does not transfer from the old leaves to the new tissues easily. Subsequently, because of the iron deficiency in the young leaves, the leaves turn yellow, resulting in a disease known as chlorosis.

Iron is the one of the most important micro minerals for the maintenance of good health. Ferritin is thought to play at least 2 important roles in plants. The first is the storage of iron (van der Mark et al., 1981; Briat et al., 1995). Iron in the soil is difficult for a plant to absorb because it is a water-insoluble compound; thus, ferritin is needed to increase the iron storage for normal growth. The second main role of ferritin is the protection of cells against the toxic effects of iron due to stress. Iron distribution is heavily regulated in mammals, partly because iron ions have a high potential for biological toxicity (Nanami et al., 2005). Ferritin expression is involved in induction by iron-overload (van der Mark et al., 1982) and, hence, protects the cell from such chemistry stress (Theil, 1987). In the MS medium [excessive stress cause by a high $\mathrm{Fe}$ (II) concentration, defined as Fe (II) concentration $>120 \mu \mathrm{mol} / \mathrm{L}$ ] or in soil [appropriate Fe (II) concentration, defined as Fe (II) concentration of 30-120 $\mu \mathrm{mol} / \mathrm{L}$ ). The iron content of the transgenic plants was more than that of the SRs; the ferritin gene showed enhanced iron absorption power, and similar results were obtained in potato, rice, and tobacco plants (Goto et al., 1998; Mata et al., 2001; Ye et al., 2008).

In MS medium, the average iron content was NT > IN, while in soil, it was IN $>$ NT. The iron content increased by 78.87 and $29.85 \%$ in the NT and IN lines, respectively, with differences in the Fe (II) concentration. Previous research showed that the introns were not "silent"; they always functioned with regard to gene expression. They enhanced the activity of the promoter (Cabello et al., 2007), participated in the quantitative determination expression of the chimeric gene (Norris et al., 1993) and controlled gene expression in cells (Weise et al., 2008). Introns can affect both the level of gene expression and its pattern, but the action mechanisms in which plant introns are involved in enhancing transcriptional and/or translational 
activity of promoters is still unknown. Thus, according to our research results, the intron of the ferritin gene appears to regulate iron absorption by a rapid increase in the Fe (II) concentration and maintaining the iron content at an appropriate level in order to avoid damage caused by iron overload. The previous research results showed that iron uptake is tightly regulated in the human body, with no regulated physiological means of its excretion. Only small amounts of iron are lost daily; thus, iron levels are mostly controlled by uptake regulation. For this reason, it is advised that people do not take iron supplements unless they suffer from severe iron deficiency (Durupt et al., 2000).

In our research, iron content of the NT transgenic lines was greater than that of the others grown in the MS medium; the IN transgenic lines exhibited the highest iron content. The difference between these 2 results may be caused by the differences in iron content between the medium and the soil. When the Fe (II) concentration was $<30 \mu \mathrm{mol} / \mathrm{L}$, it was caused by a lack of iron stress; when the Fe (II) concentration was $>120 \mu \mathrm{mol} / \mathrm{L}$, it was caused by iron over stress, and both of these conditions negatively affected plant growth. The iron concentration in the MS medium was $300 \mu \mathrm{mol} / \mathrm{L}$, the height and fresh weight of the IN transgenic lines were lower than those of the NT transgenic lines and non-transformants, thus indicating that the intron plays an inhibitory role when Fe (II) is overexpressed.

In addition to iron content, the height and fresh weight of the NT lines were greater than those of the IN lines when cultivated in the MS medium but less than those of the soilcultivated IN lines. These results confirm that the Fe content was very important for plant growth and integrity, and the intron inhibits the $\mathrm{Fe}$ (II) absorption rate when available at high concentrations. However, in the MS medium, the MDA content results showed that NT $>$ IN $>$ SR, whereas MDA levels reflected the degree of peroxidation of the membrane lipids. $\mathrm{H}_{2} \mathrm{O}_{2}$ acts as an ROS and can damage membrane lipids, proteins, and DNA (Foyer and Noctor, 2009); thus indicating that the damage level of the IN transgenic line membrane lipids was less than that of the NT lines, while SOD activity of the IN lines was greater than that of the NT lines. Moreover, the results confirm that the IN transgenic lines suffered less damage overall throughout the transgenic process.

\section{ACKNOWLEDGMENTS}

Research supported by the Hi-Tech Research and Development Program of China (\#2013AA102701) and the Fundamental Research Funds for the Central Universities Project (\#DL12CA16).

\section{REFERENCES}

Alscher RG, Erturk N and Heath LS (2002). Role of superoxide dismutases (SODs) in controlling oxidative stress in plants. J. Exp. Bot. 53: 1331-1341.

Andrews SC (1998). Iron storage in bacteria. Adv. Microb. Physiol. 40: 281-351.

Briat JF, Labouré AM, Laulhère JP and Lescure AM (1995). Molecular and Cellular Biology of Plants. Kluwer Academic Publishers, Netherlands, 265-276.

Bruce A (2008). Molecular Biology of the Cell. Garland Science, NewYork.

Cabello JV, Dezar CA, Manavella PA and Chan RL (2007). The intron of the Arabidopsis thaliana COX5c gene is able to improve the drought tolerance conferred by the sunflower Hahb-4 transcription factor. Planta 226: 1143-1154.

Carrington D (2012). GM crops good for environment, study finds. The Guardian June 13, 2012. Available at [http://www. guardian.co.uk/environment/2012/jun/13/gm-crops-environment-study?INTCMP=SRCH]. Accessed January 21, 2013. 
Carrondo MA (2003). Ferritins, iron uptake and storage from the bacterioferritin viewpoint. EMBO J. 22: 1959-1968. Darnell JE (1978). Amplications of RNA-RNA splicing in evolution of eukaryotic cells. Science 202: 1257-1260.

Dlouhy AC and Outten CE (2013). The iron metallome in eukaryotic organisms. Met. Ions. Life Sci. 12: 241-278.

Durupt S, Durieu I, Nové-Josserand R, Bencharif L, et al. (2000). Hereditary hemochromatosis. Rev. Med. Interne 21: 961-971.

Engler-Blum G, Meier M, Frank J and Muller GA (1993). Reduction of background problems in nonradioactive northern and Southern blot analyses enables higher sensitivity than 32P-based hybridizations. Anal. Biochem. 210: 235-244.

Foyer $\mathrm{CH}$ and Noctor G (2009). Redox regulation in photosynthetic organisms: signaling, acclimation, and practical implications. Antioxid. Redox. Signal. 11: 861-905.

Gilbert W (1978). Why genes in pieces? Nature 271: 501.

Giannopolitis CN and Ries SK (1977). Superoxide dismutases: I. Occurrence in higher plants. Plant Physiol. 59: 309-314.

Goto F, Yoshihara T and Saiki H (1998). Iron accumulation in tobacco plants expressing soybean ferritin gene. Transgenic Res. 7: 173-180.

Harrison PM, Hempstead PD, Artymiuk PJ and Andrews SC (1998). Structure-function relationships in the ferritins. Met. Ions. Biol. Syst. 35: 435-477.

Mata CG, Lamattina L and Cassia RO (2001). Involvement of iron and ferritin in the potato-Phytophthora infestans interaction. Eur. J. Plant Pathol. 107: 557-562.

Murray MG and Thompson WF (1980). Rapid isolation of high molecular weight plant DNA. Nucleic Acids Res. 8: 43214325.

Nanami M, Ookawara T, Otaki Y, Ito K, et al. (2005). Tumor necrosis factor- $\alpha$-induced iron sequestration and oxidative stress in human endothelial cells. Arterioscler. Thromb. Vasc. Biol. 25: 2495-2501.

Norris SR, Meyer SE and Callis J (1993). The intron of Arabidopsis thaliana polyubiquitin genes is conserved in location and is a quantitative determinant of chimeric gene expression. Plant Mol. Biol. 21: 895-903.

Pham CG, Bubici C, Zazzeroni F, Papa S, et al. (2004). Ferritin heavy chain upregulation by NF-kB inhibits TNF $\alpha$ induced apoptosis by suppressing reactive oxygen species. Cell 119: 529-542.

Proudhon D, Wei J, Briat J and Theil EC (1996). Ferritin gene organization: differences between plants and animals suggest possible kingdom-specific selective constraints. J. Mol. Evol. 42: 325-336.

Rearick D, Prakash A, McSweeny A, Shepard SS, et al. (2011). Critical association of ncRNA with introns. Nucleic Acids Res. 39: 2357-2366.

Stewart RR and Bewley JD (1980). Lipid peroxidation associated with accelerated aging of soybean axes. Plant Physiol. 65: 245-248.

Theil EC (1987). Ferritin: structure, gene regulation, and cellular function in animals, plants, and microorganisms. Annu. Rev. Biochem. 56: 289-315.

van der Mark F, de Lange T and Bienfait HF (1981). The role of ferritin in developing primary bean leaves under various light conditions. Planta 153: 338-342.

van der Mark F, van den Briel ML, van Oers JW and Bienfait HF (1982). Ferritin in bean leaves with constant and changing iron status. Planta 156: 341-344.

Weise A, Lalonde S, Kühn C, Frommer WB, et al. (2008). Introns control expression of sucrose transporter LeSUT1 in trichomes, companion cells and in guard cells. Plant Mol. Biol. 68: 251-262.

Ye HX, Li M, Guo ZJ, Shu QY, et al. (2008). Evaluation and application of two high-iron transgenic rice lines expressing a pea ferritin gene. Rice Sci. 15: 51-56. 